\title{
Log10 50 Percent Embryo Infective Dose
}

National Cancer Institute

\section{Source}

National Cancer Institute. Log10 50 Percent Embryo Infective Dose. NCI Thesaurus.

Code C70479.

A potency unit for measuring infectious activity of a biologic product or infectious agent equal to a base-10 logarithm of amount of product or agent preparation that causes infection in the $50 \%$ of embryos (such as chicken embryos) used in the product potency assay or pathogen activity assay. 